\title{
A dislocated pisiform: Case report
}

\author{
Earl AD Campbell MD FRCSC, Enzio Magi MD FRCSC \\ Department of Surgery, Division of Plastic Surgery, University of Calgary, Foothills Hospital, \\ Calgary, Alberta
}

EAD Campbell, E Magi. A dislocated pisiform: Case report. Can J Plast Surg 1999;7(2):57-58.

Dislocation of the pisiform bone is rare. The present paper describes the 12th reported case of an isolated dislocated pisiform bone and a successful treatment result from closed reduction and splinting.

Key Words: Dislocation; Pisiform

\section{Luxation du pisiforme : rapport de cas}

RÉSUMÉ : La luxation du pisiforme est rare. Le présent article décrit le $12^{\mathrm{e}}$ cas rapporté d'une luxation isolée du pisiforme et le résultat d'un traitement réussi par réduction fermée et pose d'une attelle.

$\mathrm{T}$ The pisiform bone is a sesamoid bone located within the flexor carpi ulnaris tendon. Dislocation of the pisiform bone is an unusual injury. The present report documents a case treated successfully with closed reduction.

\section{CASE PRESENTATION}

A previously healthy 33-year-old orthopedic surgery resident fell while rollerblading, landing on the ulnar and volar side of her outstretched right wrist. On presentation, she had pain and swelling on the ulnar side of her wrist and was unable to extend her wrist. Flexion of the wrist and ulnar deviation of the hand produced pain. She complained of paresthesia in the ulnar nerve distribution of the hand, and on palpation there was a mass present lateral to the hook of the hamate. Roentgenograms of the hand demonstrated a dislocated pisiform bone and a minimally displaced triquetral fracture (Figure 1).

The following day, closed reduction of the pisiform was accomplished under general anesthesia by pushing the pisiform proximally while flexing and pronating the wrist. Her upper limb was then immobilized for three weeks with her wrist pronated, flexed and ulnarly deviated. After three weeks, the splint was shortened to allow pronation and supi-

Correspondence and reprints: Dr Earl AD Campbell,

Foothills Hospital, 1403 29th Street NW, Calgary, Alberta T2N 2 T9.

Telephone 403-670-1110, fax 403-670-1277 nation, but the wrist was still held flexed and deviated ulnarly for another three weeks. Six weeks postoperatively, the splint was removed and physiotherapy was commenced. Six weeks after removing the splint, $\mathrm{x}$-rays showed that the pisiform bone had maintained its reduced position (Figure 2), and the wrist exhibited a full range of motion with pain only at the extremes of flexion and ulnar deviation. Fifteen months postinjury, the wrist was asymptomatic and the pisiform bone was still adequately reduced (Figure 3).

\section{DISCUSSION}

Dislocation of the pisiform bone is a very rare occurrence. To date, there have only been 11 reported cases of isolated pisiform dislocation (1-10), plus an additional three cases of combined hamate and pisiform dislocation $(11,12)$. The anterior aspect of the pisiform is dome shaped and covered with soft tissue attachments including the flexor carpi ulnaris tendon, transverse carpal ligament, abductor digiti minimi, extensor retinaculum, pisometacarpal ligament, pisohamate ligament, pisotriquetral joint capsule and a band extending to the hook of the hamate. Rather than imbedding the pisiform, the flexor carpi ulnaris attaches to the anterior aspect of the pisiform (13). Because the articulation of the pisiform on the hamate is almost flat, the pisiform relies on these soft tissue attachments for its stability. While all of these structures provide support, the flexor carpi ularnis tendon is the most substantial proximal stabilizer of the pisiform. The normal 


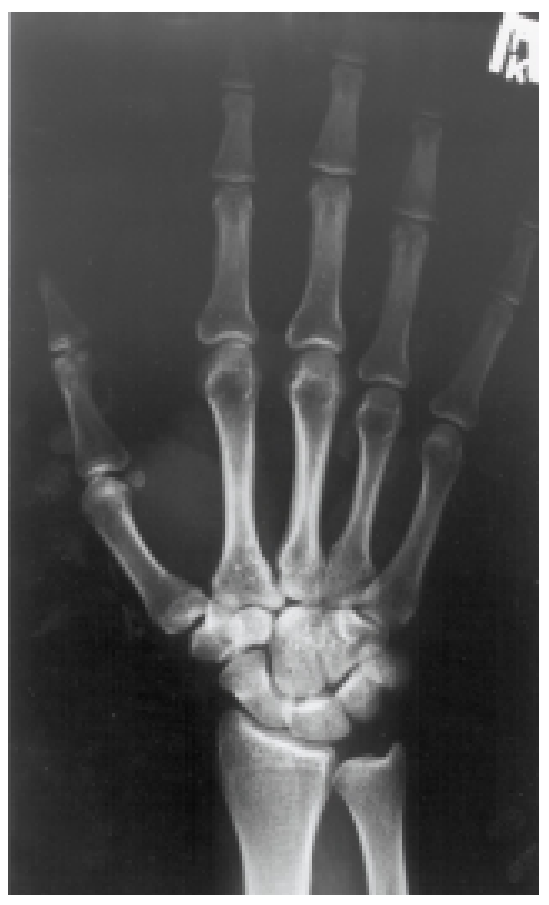

Figure 1) $X$-ray on presentation showing the dislocated pisiform bone

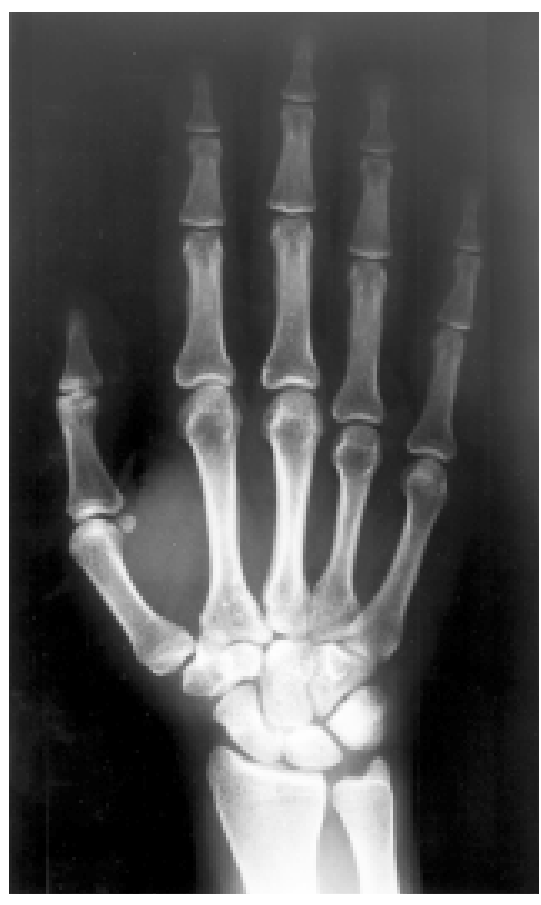

Figure 2) X-ray showing the pisiform bone immediately postreduction

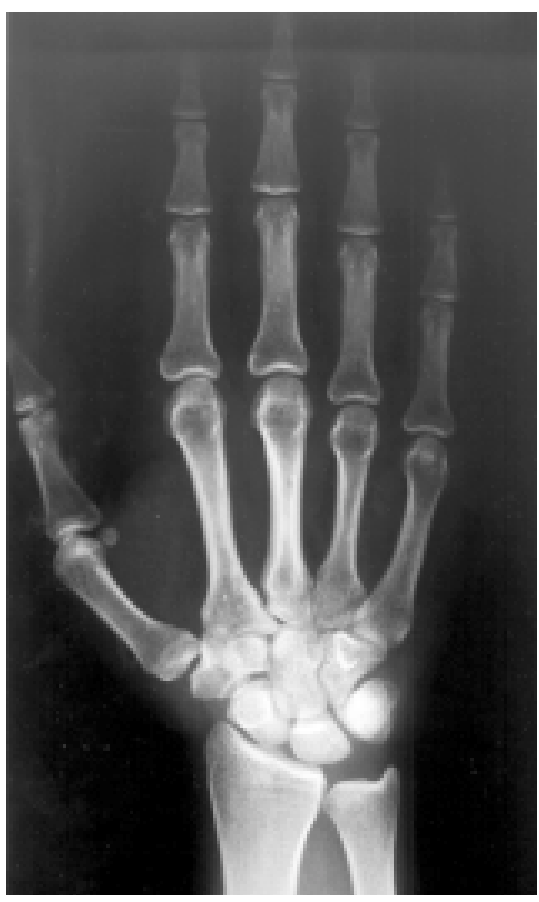

Figure 3) X-ray showing the pisiform bone 15 months postreduction forces of the flexor carpi ularnis pull the pisiform proximally. Therefore, the lateral structures, including the transverse carpal ligament and anterior carpal ligament, are more developed and stronger than the medial soft tissue attachments (13).

The pisiform bone acts as a lever to increase the force of wrist flexion supplied by the flexor carpi ulnaris. It also distributes the pull of the flexor carpi ulnaris to the pisometacarpal and pisohamate ligaments to aid wrist flexion (13).

The pathogenesis of a dislocated pisiform remains obscure, but there are two probable mechanisms. Direct force applied to the pisiform bone may result in a dislocation. Alternatively, acute dorsiflexion of the wrist with the flexor carpi ulnaris already contracted and the wrist flexed may cause the pisiform bone to become dislocated (6). It is more likely that our patient's injury was caused by direct force applied to the pisiform bone.

Treatment of a dislocated pisiform can be either surgical or nonsurgica1 (6). Ozzene (3) and Mather (4) treated dislocation of the pisiform bone by repositioning and immobilizing it. Unfortunately, this procedure produced unsatisfactory results. However, Sharara and Farrar (8) reported a successful closed reduction and attributed this to keeping the wrist pronated and flexed to relieve tension in the flexor carpi ulnaris. Alternatively, Minami et al (6) and Ishizuki et al (7) advocated resection of the pisiform. Each of their patients had an asymptomatic wrist postoperatively. Resection of the pisiform bone is supported by Jenkins (14), who states that the pain will persist if the pisiform is unstable on the tri- quetrum, and osteoarthritis of the piso-triquetral joint will be a likely sequela with pisotriquetral instability. We performed a closed reduction and immobilization of the pisiform advocated by Sharara and Farrar (8), which produced a satisfactory result.

\section{REFERENCES}

1. Cohen I. Dislocation of the pisiform. Ann Surg 1922;75:238-9.

2. Immermann EW. Dislocation of the pisiform. J Bone Joint Surg 1948;30:489-92.

3. Ozzene E. Deux cas de luzation du pisiform. Chirurgie 1911;3:559.

4. Mather JH. Dislocation of the pisiform bone. Br J Radiol 1924;29:17-8.

5. Sugawara T, Nakazawa S. A case of dislocation of the pisiform. J Jpn Orthop Assoc 1957;31:104.

6. Minami M, Yamazaki J, Ishii S. Isolated dislocation of the pisiform: a case report and review of the literature. J Hand Surg [Am] 1984;9A:125-7.

7. Ishizuki M, Nakagawa T, Itoh S, Furuya K. Positional dislocation of the pisiform. J Hand Surg [Am] 1991;16:533-5.

8. Sharara KH, Farrar M. Isolated dislocation of the pisiform bone. J Hand Surg [Br] 1993;18:195-6.

9. McCarron RF, Coleman W. Dislocation of the pisiform treated by primary resection. Clin Orthop 1989;241:231-3.

10. Demartin F, Quinto O. Isolated dislocation of the pisiform. A case report. Chir Organi Mov 1993;78:121-3.

11. Pai C, Wei DC, Hu ST. Carpal bone dislocations: an analysis of twenty cases with relative emphasis on the role of crushing mechanisms. J Trauma 1993;35:28-35.

12. Gainor BJ. Simultaneous dislocation of the hamate and pisiform: a case report. J Hand Surg 1985;10:88-90.

13. Pevny T, Rayah GM, Egle D. Ligamentous and tendinous support of the pisiform, anatomic and biomechanical study. J Hand Surg 1995:20:299-304.

14. Jenkins SA. Osteoarthritis of the pisiform-triquetral joint. Report of three cases. J Bone Joint Surg 1951;33:532-4. 